\title{
Compreendendo os Mecanismos Utilizados nos Processos de Outsourcing de Software para Administração Pública Municipal
}

\author{
Cleber de Almeida ${ }^{1,2}$, Sheila Reinehr ${ }^{2}$, Andreia Malucelli ${ }^{2}$ \\ ${ }^{1}$ Universidade do Contestado - UNC \\ Núcleo de Porto União - Ciência da Computação \\ Rua Joaquim Nabuco, 314 - Bairro Cidade Nova \\ CEP 89400-000 - Porto União - SC - Brasil \\ cleberdwrnet.com.br \\ ${ }^{2}$ PontifíciaUniversidade Católica do Paraná - PUCPR \\ Programa de Pós-Graduação em Informática- PPGIa \\ Rua Imaculada Conceição, 1155 - Prado Velho \\ CEP 80215-901 - Curitiba - PR - Brasil \\ sheila, reinehr@pucpr.br, malueppgia.pucpr.br
}

\begin{abstract}
Information Technology outsourcing has been adopted as a regular practice in all kinds of organization, whether public or private. This paper discusses the mechanisms used by Municipal Public Administration Bodies. The case studies were conducted in counties that are part of a small region known as AMCESPAR (Association of the Counties of the Central South Region of Parana). Based on the data analyzed, this papers aims at presenting the current scenario of the processes that are being used for software outsourcing by the municipal public administration in this region.
\end{abstract}

Resumo. A prática de terceirização de serviços de Tecnologia da Informação incorporou-se ao cotidiano de todos os tipos de organização, quer sejam públicas ou privadas. Este artigo analisa os mecanismos utilizados nos processos de terceirização de software em Órgãos de Administração Pública Municipais. Os estudos de caso foram conduzidos em municípios que compõem a microregião denominada AMCESPAR (Associação dos Municípios da Região Centro Sul do Paraná). Com base nos dados analisados procura-se demonstrar o atual cenário referente aos processos utilizados para contratação de software para apoiar a gestão pública municipal nesta microrregião.

\section{Introdução}

Atualmente todos os setores da administração pública, independentemente do seu nível, possuem uma grande dependência do setor de Tecnologia da Informação (TI) para o desenvolvimento de suas atividades cotidianas, quer sejam operacionais, quer sejam de gestão. Dentre os recursos de TI necessários, destaca-se a importância do uso de softwares de apoio à gestão pública. Estes, geralmente, adquiridos de terceiros. 
De acordo com o Observatório SOFTEX (SOFTEX 2009a), as compras governamentais são procedimentos formais através dos quais o Estado adquire mercadorias e serviços para fins próprios e estas compras representam uma parcela significativa do PIB de qualquer país. Os autores afirmam ainda que o poder de compra do governo constitui uma peça importante da política de desenvolvimento nacional, estimulando os negócios de micro e pequenas empresas. Em 2008, as compras governamentais federais de empresas da $\operatorname{IBSS}^{1}$ totalizaram R $\$ 2,2$ bilhões. Estes gastos foram distribuídos nos vários tipos de atividades relacionadas a software, como aquisição de produtos e serviços, desenvolvimento de software sob encomenda, suporte técnico etc.

Sabe-se que a Administração Pública é um dos maiores adquirentes de produtos e serviços de software, porém, há indícios de que tem passado por dificuldades para gerir os processos de aquisição de produtos e serviços de software, desde a determinação do que comprar, até o acompanhamento e aceitação dos projetos de desenvolvimento de software (Cardoso 2006).

Uma revisão sistemática da literatura realizada por Nunes et. al (2010), identificou que as principais causas de insucesso dos projetos de software adquiridos são os problemas no gerenciamento, as definições incompletas de requisitos, a seleção inadequada de fornecedor e de processo de contratação, a falta de controle de mudança dos requisitos, os contratos ineficientes, a falta de comunicação, e a falta de processos para a aquisição de software adequado às necessidades da organização, sendo esta última a mais citada entre os documentos pesquisados.

As práticas de gerenciamento são um dos maiores problemas detectados nas aquisições de software. A imaturidade de uma organização na contratação de um software tem o mesmo potencial de fracasso que aquele desenvolvido por uma organização que não possui um processo de desenvolvimento maduro (Santos 2009). A opção por outsourcing de software para estes órgãos acaba sendo o caminho mais rápido, contudo o sucesso ou insucesso do projeto deve estar atrelado à utilização de boas práticas de gerência de software para apoiar as etapas que compõem este processo.

Além da falta de adoção de boas práticas nos processos de outsourcing de software, o Guia PrATIco (Laboratório Synergia2010) aponta a carência de pessoal capacitado em aquisições, como um fator fundamental para o insucesso dos projetos de aquisição de produtos de software na administração pública. Uma das consequências mais comuns neste caso é a exposição da administração pública a fornecedores mal intencionados que acabam aproveitando a situação para explorar os cofres públicos com contratos de prestação de serviços com valores exorbitantes.

Como poderá ser observado na seção 2 deste artigo, este cenário se torna mais evidente quando analisado em prefeituras de municípios de pequeno porte, cuja estrutura administrativa é mais enxuta. Surge assim a necessidade do uso de boas práticas de melhoria de software, voltadas para processos de outsourcing, visando aprimorar os projetos de escolha de fornecedor, contratação dos serviços, além de implantação e suporte de softwares para gestão pública municipal.

\footnotetext{
${ }^{1}$ IBSS: Indústria Brasileira de Software e Serviços de Tecnologia da Informação (TI).
} 
Diante do cenário exposto, este artigo tem como objetivo discutir como os setores da Administração Pública Municipal, da microrregião analisada, conduzem atualmente seus processos de terceirização de software para apoiar as atividades inerentes à gestão pública municipal. Outra contribuição refere-se ao cenário analisado, pois durante a revisão bibliográfica não foram encontrados trabalhos sobre outsourcing direcionados à Administração Pública Municipal.

Este artigo está assim organizado: a seção 2 apresenta o cenário atual dos processos de outsourcing em Prefeituras Municipais que compõem a microrregião AMCESPAR; a seção 3 aborda os procedimentos metodológicos; a seção 4 apresenta os resultados do trabalho, os quais são discutidos na seção 5; e, finalmente, a seção 6 conclui as análises e apresenta perspectivas de trabalhos futuros.

\section{Terceirização em Tecnologia da Informação}

Hoje, mais do que nunca, as organizações de todos os setores estão se tornando adquirentes das capacidades que necessitam, obtendo cada vez mais produtos e serviços de fornecedores externos e desenvolvendo cada vez menos estas capacidades internamente. O objetivo desta estratégia, cada vez mais utilizada, é aumentar a eficiência operacional da organização, a custos mais baixos e usando a tecnologia mais adequada (SEI 2007).

A terceirização se apresenta, nesse cenário, como uma ferramenta adequada, já que repassa a especialistas em determinada área, parte das atividades da empresa, reduzindo com isso seus custos e aumentando a eficiência nos serviços prestados (Saraiva e Moura 2010).

Cada vez mais as organizações têm adquirido soluções de tecnologia, obtendo serviços de desenvolvimento de software junto a fornecedores externos. A necessidade de se obter soluções atendendo a padrões de qualidade cada vez mais altos, com rapidez, custo baixo e com as tecnologias apropriadas é crescente (Abreu, Farias e Albuquerque 2010).

Segundo Santos (2009), nos últimos anos, muitas organizações têm delegado atividades de TI para terceiros, de forma a ter mais recursos livres para dedicarem-se às suas competências principais, ou mesmo pela falta de capacidade para acompanhar a rápida evolução da TI. Para tal, as organizações devem ter uma estrutura que permita a gerência eficaz de todos os contratos de software para que se obtenha os benefícios da contratação.

Este fenômeno tem ocorrido tanto no âmbito das empresas privadas, quanto no âmbito dos órgãos públicos, sejam federais, estaduais ou municipais. Independentemente do tamanho do município analisado, o uso de softwares para apoiar a gestão pública municipal é imprescindível e o desenvolvimento de soluções específicas dentro da própria administração pública pode se tornar demorado e muito oneroso. Isto pode ocorrer devido à escassez de mão-de-obra especializada em desenvolvimento de software na região do município. Outro fator que colabora para um cenário propício para processos de outsourcing de software para gestão pública municipal é que empresas de desenvolvimento de software focadas neste nicho de mercado têm o know-how da implantação de outros projetos bem sucedidos, o que garante sua experiência neste setor. 
No âmbito de aquisição de software, devido à crescente busca por qualidade e a necessidade de atualizações frequentes, o processo de outsourcing de software tem se tornado uma prática comum no setor público.

A atividade de outsourcing pode ser definida como a transferência da responsabilidade do gerenciamento contínuo do fornecimento de um serviço para um terceiro, administrada por um acordo dos níveis dos serviços estabelecidos. O processo de outsourcing passou por vários estágios, surgiu primeiramente para suprir a falta de recursos financeiros, bem como a falta de talentos internos para execução das atividades, passando por fim a ser considerado um processo de suma importância nas organizações, valorizando os benefícios que os especialistas externos podem agregar ao negócio (Figueiredo, Bremer e Maldonado 2003).

Em uma pesquisa realizada em 2008 sobre as perspectivas do gerenciamento dos processos de outsourcing de software, os autores observaram que havia uma grande necessidade das organizações por projetos de outsourcing e que os serviços de TI caminhavam cada vez mais rumo a esta modalidade de relação de negócios (Casey, Deshpande e Richardson 2008).

Os processos de outsourcing de software deixaram de ser uma tendência e tornaram-se um fator comum nas relações de aquisição de software. Inúmeras pesquisas abordam o tema principalmente focando a parte legal ou os modelos de formalização das relações de outsourcing.

No entanto, diversas são as dificuldades encontradas nestes processos. Em recente pesquisa identificou-se que 20 a $25 \%$ dos grandes projetos de aquisição de TI falham em dois anos e 50\% falham em até cinco anos (SEI 2007).

Para gerenciar os processos de outsourcing, as organizações públicas ou privadas podem se valer de diversas normas e modelos que versam sobre aspectos que devem ser observados para que exista qualidade na aquisição de software e, consequentemente, o projeto de aquisição possa ser considerado bem sucedido. Entre os modelos e normas que recomendam boas práticas na aquisição de software pode-se citar:

- CMMI-ACQ v1.2 (SEI 2007): coleção de boas práticas desenvolvidas pelo SEI para serem aplicadas à aquisição de produtos e serviços de software;

- eSCM-CL v1.1 (ITSqc 2009a) (ITSqc 2009b): modelo de capacidade em eSourcing para organizações clientes, desenvolvido pelo ITSqc;

- Norma ISO/IEC 15504 (ISO/EC 1998): define os procedimentos para avaliação da capacidades dos processos de uma organização, podendo ser utilizada para avaliar possíveis fornecedores;

- Guia PraTICo: desenvolvido pelo Laboratório Synergia da UFMG para ser utilizado pelo Governo de Minas Gerais (Laboratório Synergia 2006); e

- Guia de Aquisição do programa para a Melhoria de Processo do Software Brasileiro (MPS.BR) (SOFTEX 2009b): descreve o processo de aquisição que pode ser implementado em uma organização que adquire produtos e/ou serviços de software.

\subsection{CMMI-ACQ v1.2}

Desenvolvido a partir das orientações contidas no modelo CMMI, o modelo denominado CMMI-ACQ v1.2 descreve um conjunto de boas práticas para orientar 
processos de aquisição de software (SEI 2007). Todas as atividades definidas referemse ao lado do adquirente, ou seja, a organização que adquire o produto e/ou serviço de software.

Ao todo são definidas 22 áreas de processo, agrupadas em quatro categorias: processos organizacionais, processo de projeto, processos de apoio e processos de alta maturidade. Destas áreas de processo, 16 são áreas comuns, provenientes do modelo base CMMI e 6 são específicas para atender às necessidades do processo de aquisição (gerenciamento do acordo, desenvolvimento dos requisitos de aquisição, gerenciamento técnico da aquisição, validação da aquisição, verificação da aquisição e desenvolvimento do acordo de fornecimento).

Os seguintes graus de institucionalização são estabelecidos pelo modelo: Nível 1 (Executado), Nível 2 (Gerenciado), Nível 3 (Definido), Nível 4 (Quantitativamente Gerenciado) e Nível 5 (Em Otimização). A exemplo do conhecido CMMi-DEV, estes níveis são implementados por meio de objetivos e práticas genéricas.

\section{2. eSCM CL v1.1}

O Information Technology Services Qualification Center (ITSqc), um spinoff da Carnegie Mellon University, desenvolveu modelos de capacidade para melhorar o relacionamento entre provedores de serviço e seus clientes (eSourcing Capability Model for Service Providers - eSCM-SP) e um modelo para contratação de serviços com foco nas organizações clientes (eSourcing Capability Model for Client Organizations eSCM-CL), segundo (Abreu, Farias e Albuquerque 2010).

O consórcio ITSqc foi originalmente composto por diversos stakeholders envolvidos no fornecimento/aquisição de serviços de TI, tais como: Accenture, CA, DBA, HP entre outros (ITSqc 2009a).

O eSCM-CL possui ao todo 95 práticas focadas na melhoria do processo da organização adquirente, ou seja, o cliente. As práticas cobrem desde o desenvolvimento das estratégias para a contratação de produtos e/ou serviços, até a integração do item adquirido ao dia a dia de sua operação. Estas práticas estão distribuídas em três dimensões: ciclo de vida do fornecimento, área de capacidade e nível de capacidade. Descrições completas podem ser encontradas em ITSqc (2009a) e ITSqc (2009b).

\subsection{ISO/IEC 15504}

A Norma Internacional ISO/IEC 15504 (ISO/IEC 1998) representa um guia para a avaliação de capacidade de processos de software, focando dois objetivos: a melhoria de processos e a determinação da capacidade de processos de uma organização, este último de maior interesse no processo de aquisição.

Se o objetivo for a melhoria de processos, a organização pode realizar a avaliação gerando um perfil dos processos que será usado para a elaboração de um plano de melhorias. A análise dos resultados identifica os pontos fortes, os pontos fracos e os riscos inerentes aos processos. No segundo caso, a empresa tem o objetivo de avaliar um fornecedor em potencial, obtendo o seu perfil de capacidade. O perfil de capacidade permite ao contratante estimar o risco associado à contratação daquele fornecedor em potencial para auxiliar na tomada de decisão de contratá-lo ou não (Cardoso 2006). 


\subsection{Guia PrATIco}

A abordagem do PrATIco (Laboratorio Synergia 2006) mostra-se ser bem planejada e abrangente, contemplando de forma ampla as fases de planejamento, contratação, execução do contrato, aceitação do produto ou serviço e uso efetivo da solução. A metodologia dispõe ainda de uma ferramenta base web para fazer todo o acompanhamento destas fases, uma espécie de manual que guia o comprador nas fases e artefatos que deverão ser produzidos. Isto se faz necessário, pois a aquisição de software na Administração Pública está submetida à lei 8666/93 que regulamenta os aspectos legais da aquisição de qualquer produto ou serviços por órgãos públicos e define os modos de aquisições e contratos (Ferreira, Júnior e Souza 2008).

\subsection{MPS.BR - Guia de Aquisição}

O programa MPS.BR é uma iniciativa da SOFTEX, com apoio de outros organismos, para a promoção da qualidade nas empresas de software do Brasil. No escopo deste programa foi desenvolvido o MR-MPS, que é o Modelo de Referência para a melhoria de processos de software utilizado como base para promover melhorias em empresas de software em geral, como foco principal em micro, pequenas e médias empresas. Além deste, o MPS.BR desenvolveu o Guia de Aquisição (SOFTEX 2009b) que descreve e propõe um processo de aquisição de software baseado na norma ISO/IEC 12207:2008, complementado pela norma IEEE STD 1062:1998.

O Guia de Aquisição do MPS foca a descrição do processo de aquisição, baseado na ISO/IEC 12207:2008, a partir de suas quatro atividades fundamentais: preparação da aquisição, seleção do fornecedor, monitoração do contrato e aceitação pelo cliente (SOFTEX 2009b). Além da descrição das atividades, insumos e resultados envolvidos no processo de aquisição, este guia apresenta, em anexos, exemplos de modelos de documentos produzidos ao longo do processo, que poderão ser personalizados conforme a necessidade das organizações que pretendam adotar este processo (Ferreira, Júnior e Souza 2008).

\section{Metodologia}

\subsection{Questão de pesquisa}

A questão principal que esta pesquisa visa responder é: quais são os mecanismos utilizados pela administração pública municipal para selecionar fornecedores de produtos e/ou serviços de tecnologia da informação?

\subsection{Seleção do método de pesquisa}

Considerando: (i) se tratar de uma pesquisa descritiva na qual o pesquisador investiga fenômenos contemporâneos; (ii) que o pesquisador não detém controle sobre os fenômenos investigados; (iii) as orientações de Yin (2005), Gil (2002) e Lakatos e Marconi (2005) sobre a seleção de métodos de pesquisa; o método selecionado para a condução do estudo de campo foi o estudo de caso.

De acordo com Yin (2005), o estudo de caso se aplica quando "(...) faz-se uma questão do tipo como e por que sobre um conjunto contemporâneo de acontecimentos, sobre o qual o pesquisador tem pouco ou nenhum controle". 
Segundo Gil (2002), as pesquisas do tipo estudo de caso caracterizam-se pelo estudo profundo e exaustivo de um ou poucos objetos, com o objetivo de adquirir amplo e detalhado conhecimento sobre este(s). Utiliza-se o conceito de objeto único, ou caso único, quando existe uma situação (objeto de estudo) que por si só pode caracterizar definitivamente a conclusão. Neste caso, como não existe o caso único, ou caso revelador, optou-se pelo estudo de múltiplos casos. Além de aprofundar as descobertas acerca do fenômeno estudado, a utilização de múltiplos casos contribui substancialmente para os procedimentos de generalização subsequentes à investigação de campo inicial.

O estudo de caso foi conduzido seguindo as seguintes etapas:

- seleção dos casos a serem estudados;

- concepção do instrumento de apoio (questionário a ser utilizado como apoio ao processo de entrevistas semi-estruturadas);

- contato inicial com a prefeitura para obter autorização para a condução da pesquisa;

- condução das entrevistas presenciais semi-estruturadas;

- tabulação dos dados e análises;

- elaboração das conclusões.

\subsection{Seleção dos casos a serem estudados}

Para a compreensão acerca de como os municípios tratam a questão da terceirização de serviços de TI era necessário selecionar municípios que pudessem adequadamente representar a população sendo investigada e, além disto, que houvesse a possibilidade do pesquisador ter acesso aos responsáveis pelo processo para entrevistá-los. Desta forma, foram selecionados municípios do estado do Paraná, conforme descrito a seguir.

O Estado do Paraná encontra-se subdividido geograficamente em 10 mesorregiões e 39 microrregiões. Para este estudo foi selecionada a microrregião AMCESPAR (Associação dos Municípios da Região Centro Sul do Paraná), pela facilidade de acesso do pesquisador aos municípios que a compõem e por sua característica de conter municípios de pequeno porte.

Fundada em 1983, a AMCESPAR tem por finalidade a integração regional, econômica e administrativa dos municípios associados, visando ampliar e fortalecer sua capacidade administrativa, sempre em busca da defesa dos interesses dos associados e da microrregião como um todo (AMCESPAR 2010).

A microrregião AMCESPAR é composta por 10 municípios, sendo eles: Irati (sede da microrregião), Fernandes Pinheiro, Guamiranga, Inácio Martins, Ipiranga, Mallet, Prudentópolis, Rebouças, Rio Azul e Teixeira Soares. Cerca de 80\% deles possui menos de 15.000 habitantes, com exceção de Irati e Prudentópolis que possuem mais de 50.000 habitantes (AMCESPAR 2010).

\subsection{Concepção do instrumento de apoio}

Para facilitar a condução das entrevistas, visando obter o máximo de informações em curto espaço de tempo, otimizando os recursos, optou-se pela definição de um questionário de apoio. 
O questionário era composto por questões fechadas (respostas objetivas, previamente planejadas para permitir rápido mapeamento de caracterizações iniciais) e questões abertas (visando coletar informações mais detalhadas acerca do cenário estudado). O Quadro 1 apresenta as questões de apoio utilizadas como base para a condução das entrevistas.

Quadro 1. Questionário de apoio para as entrevistas semiestruturadas.

\section{Questão}

Q1- A Prefeitura possui software voltado para gestão pública municipal?

Q2 - Qual modelo de relacionamento comercial é utilizado para uso do software?

Q3 - Qual fornecedor?

Q4 - Este fornecedor possui alguma avaliação publicada quanto ao seu nível de maturidade em desenvolvimento de software?

Q5 - Quais fatores influenciaram a prefeitura no momento da contratação do software?

Q6 - No momento da contratação do sistema de gestão, alguma norma ou modelo de boas práticas para gestão de aquisição de software foi observada?

Q7- Existe, no quadro de funcionários, algum profissional capacitado para gerenciar os projetos de aquisição de software dentro da prefeitura?

\section{Objetivo da Questão}

Direcionar a pesquisa. Caso a resposta fosse negativa, deixaria de existir motivo para dar continuidade à pesquisa.

Determinar o tipo de relacionamento comercial existente entre as instituições e as empresas fornecedoras de soluções de software.

Descobrir quais empresas atuam na região, possibilitando análise posterior destes fornecedores para identificar quais possuem avaliação de nível de maturidade em desenvolvimento de software.

Descobrir se os entrevistados possuíam alguma informação referente à avaliação do nível de maturidade dos seus fornecedores.

Compreender os mecanismos utilizados para realização de outsourcing de software nas prefeituras pesquisadas.

Identificar se alguma norma ou modelo de boas práticas para aquisição de software foi levado em consideração ou fez parte dos processos de outsourcing.

Identificar se dentro do quadro de funcionários municipais existia algum funcionário capacitado para aplicar normas e modelos de boas práticas de terceirização de TI.

\subsection{Condução da pesquisa}

O contato inicial com as prefeituras da microrregião visou apresentar os objetivos da pesquisa, bem como identificar a disponibilidade do município para participar. Todas as prefeituras da microrregião estudada aceitaram participar da pesquisa e indicaram os responsáveis para participar das entrevistas e contribuir com suas informações acerca do processo de terceirização de TI.

Foram então conduzidas as entrevistas presenciais apoiadas pelo questionário. Todos os entrevistados responderam a todas as questões propostas. Os resultados encontram-se detalhados na próxima seção. 


\section{Resultados}

O primeiro aspecto (Q1) abordado pela pesquisa foi analisar quais prefeituras, dentre as pesquisadas, possuem algum tipo de software para apoiar suas atividades de gestão, caso contrário não haveria justificativa para continuar com a pesquisa. Neste aspecto, $100 \%$ das prefeituras respondentes da pesquisa disseram que possuem algum tipo de software voltado para gestão pública municipal, o que permitiu realizar a pesquisa com $100 \%$ das prefeituras desta microrregião.

\subsection{Modelo de Contratação}

O segundo aspecto tratado (Q2) foi identificar o modelo de relacionamento comercial utilizado para uso do software, visando descobrir quais possuem o modelo de terceirização.

Observou-se que $100 \%$ das prefeituras respondentes optam pelo modelo de terceirização para aquisição de softwares para gestão. Entre as justificativas obtidas junto aos entrevistados, destacam-se: a falta de pessoal interno capacitado para desenvolvimento de software, e as estimativas de custo que apontam para a modalidade de terceirização como a menos onerosa.

Outro fator que pode ser citado, é que a maioria das prefeituras entrevistadas possui empresas que prestam consultoria na área contábil. Quando estas empresas são contratadas, trazem atreladas aos seus serviços, softwares de gestão de terceiros. Um dos requisitos da contratação é normalmente a adoção deste sistema para viabilizar a consultoria. Como estas consultorias têm prazo de atuação entre 4 e 8 anos, dependendo do tempo de mandato do gestor, mais uma vez ocorre a opção por terceirização.

\subsection{Fornecedores que atuam na microrregião}

Em seguida buscou-se identificar quais fornecedores de software de gestão atuam na região pesquisada (Q3). Neste momento houve um fator inesperado: três prefeituras informaram que possuíam sistemas instalados de diferentes fornecedores, o que, segundo os entrevistados, dificulta muito o processo de gestão, pois os sistemas não possuem qualquer tipo de integração entre si.

Conforme se pode observar na Figura 1, há o predomínio de um fornecedor que atua em 50\% dos municípios pesquisados. Algumas das justificativas para isto incluem:

- a plataforma de software já estar instalada há muitos anos;

- os usuários já estarem adaptados; e,

- o fato de que nos certames licitatórios não aparecem propostas de outros fornecedores. 


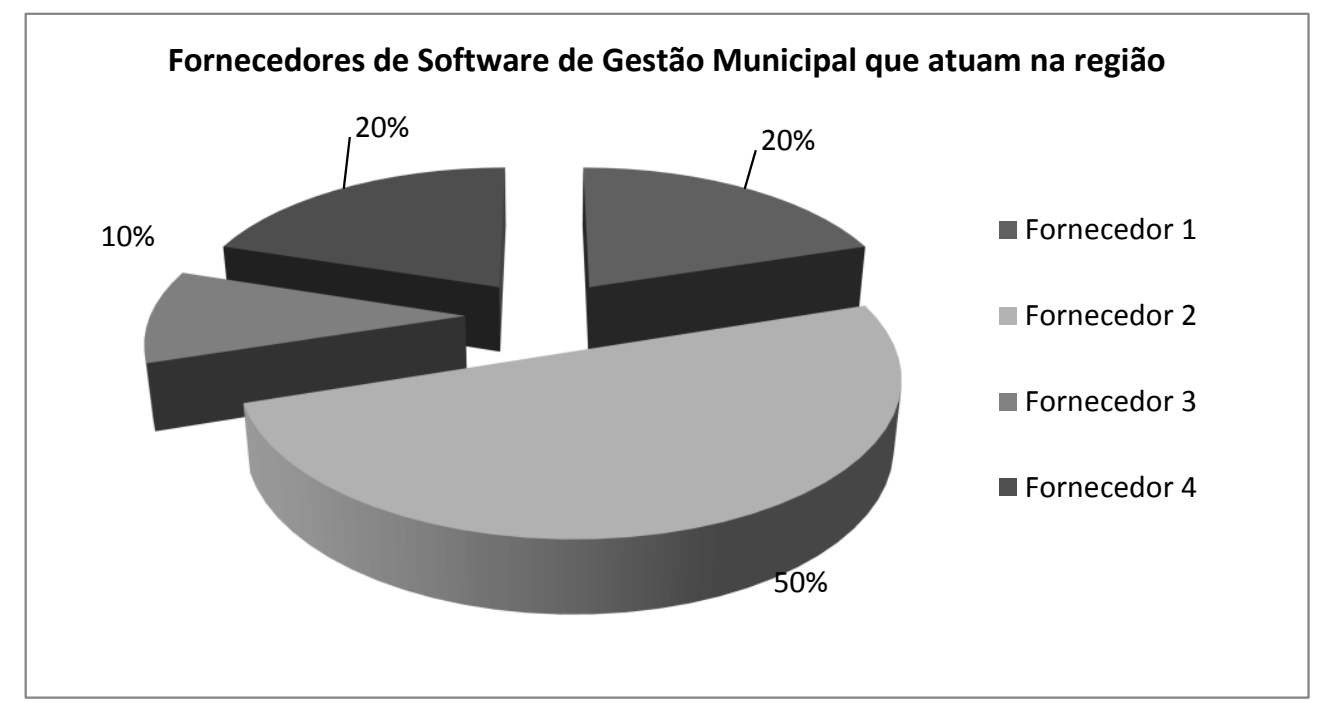

Figura 1.Distribuição dos fornecedores que atuam na microrregião AMCESPAR

O fato de algumas prefeituras entrevistadas possuírem softwares de gestão de mais de um fornecedor, exigiu um aprofundamento no assunto para que fosse possível entender a dinâmica deste cenário. Quando se fala em software de gestão, se imagina um sistema integrado capaz de fornecer informações precisas em tempo real sobre o ambiente que está sendo gerenciado.

Durante esta investigação mais apurada, percebeu-se que todas as prefeituras consideram o setor de contabilidade o cerne do processo de gestão na administração pública, e sendo este o setor responsável pelos processos de terceirização na área de software, também foi nele que foi encontrada a maior incidência desta situação, ou seja, o setor contábil usa o sistema de um fornecedor, enquanto outros setores da administração pública utilizam um sistema de fornecedor diferente.

Dentro desta questão sugiram dois cenários distintos. No primeiro caso, o sistema do setor contábil é o que está a mais tempo instalado na prefeitura, porque os funcionários deste setor estão adaptados ao sistema e resistem à mudança. No segundo caso, encontrou-se o inverso, tendo o setor contábil optado por um software que atendesse de forma mais adequada suas necessidades, enquanto outros setores continuaram utilizando a plataforma antiga, seja em virtude da falta de recursos para migração total do sistema ou por uma questão de adaptação do sistema e substituição gradativa do sistema de gestão.

Seja qual for o cenário, em um ponto todos os entrevistados foram unânimes, a falta de integração gerada pelo uso de plataformas de gestão distintas traz um sério prejuízo para administração pública no momento da integração dos dados para geração de informações importantes para auxiliar no processo de gestão.

Sendo assim, para ser possível identificar as empresas foi adotado como critério, assumir como fornecedor principal, e consequentemente associado a esta pesquisa, o fornecedor que possuía a maior base de software instalada dentro da prefeitura analisada, ou seja, aquele que possuía seu software gerindo o maior número de departamentos dentro da administração, principalmente no setor contábil considerado um dos mais importantes dentro do sistema de gestão. 


\subsection{Maturidade dos fornecedores}

Outro aspecto observado foi em relação ao conhecimento, por parte das prefeituras, a respeito do nível de maturidade dos seus fornecedores (Q4). Conforme demonstrado na Figura 2, 90\% dos respondentes desconheciam o nível de maturidade da empresa e se esta havia ou não passado por algum processo de avaliação usando modelo de referência (CMMI ou MPS, por exemplo). Apenas 10\% tinham conhecimento da maturidade da empresa fornecedora. Durante as entrevistas foi percebido que muitos entrevistados desconheciam a finalidade de uma avaliação de maturidade e, até mesmo, desconheciam modelos de referência, como os descritos na seção 2 deste artigo.

Posteriormente à pesquisa de campo, comprovou-se pelo site da SOFTEX (SOFTEX 2011) que apenas um dos fornecedores citado nesta pesquisa possuía avaliação MPS publicada. Também se buscou durante o desenvolvimento desta pesquisa informações sobre as demais empresas, porém, apenas o fornecedor indicado como possuindo avaliação publicada e listado na página da SOFTEX, possuía informações quanto ao nível de maturidade.

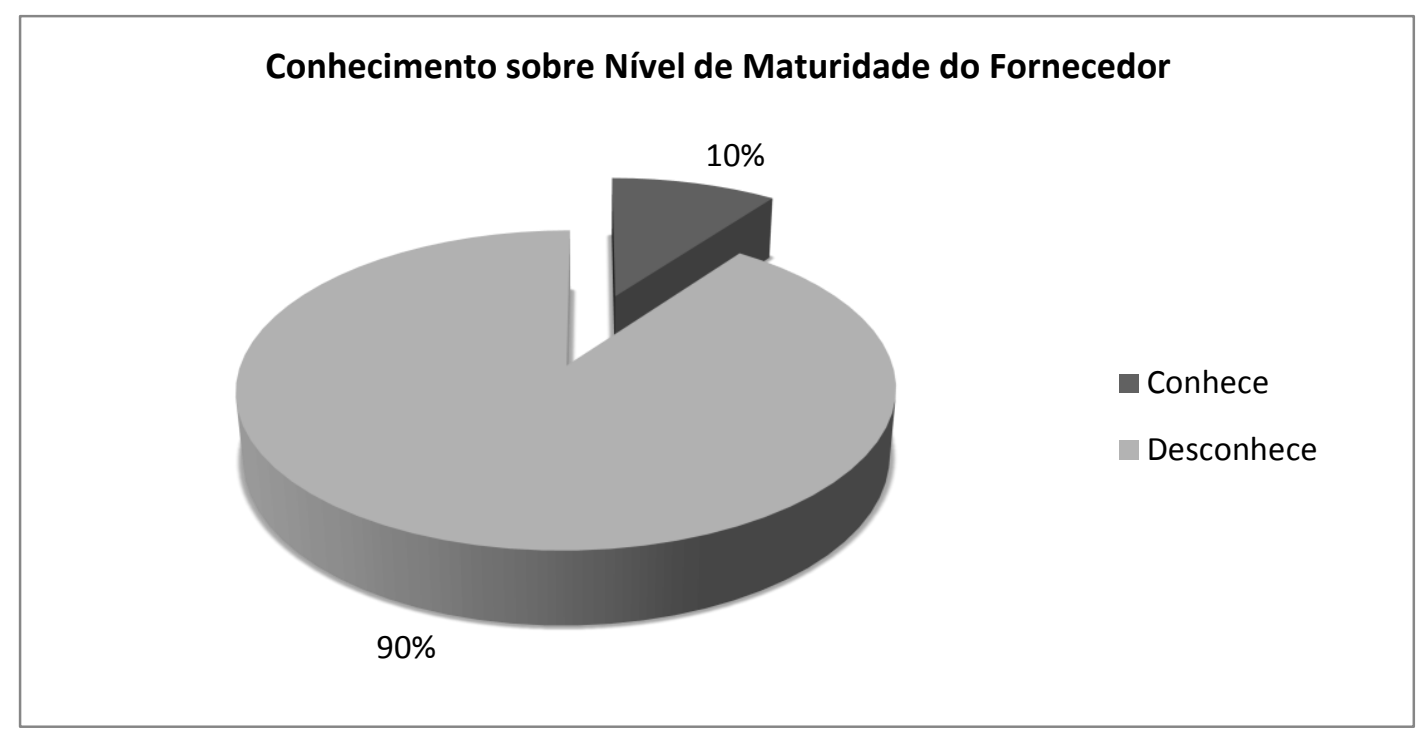

Figura 2. Distribuição das prefeituras que possuem informação referente à avaliação do nível de maturidade dos seus fornecedores

\subsection{Critérios utilizados para seleção do fornecedor}

Buscou-se compreender também quais são os fatores que influenciaram a prefeitura no momento da contratação do software de gestão (Q5). Conforme se pode observar na Figura 3, apenas $10 \%$ dos respondentes levaram em consideração a qualidade de software e o valor do sistema, sendo que $60 \%$ seguiram a indicação profissional e $20 \%$ a indicação de outras prefeituras. Explorando esta questão durante a entrevista, notou-se que, na maioria das vezes, a indicação profissional é de profissionais ligados à área administrativa ou contábil e não de profissionais ligados diretamente à área de TI. 


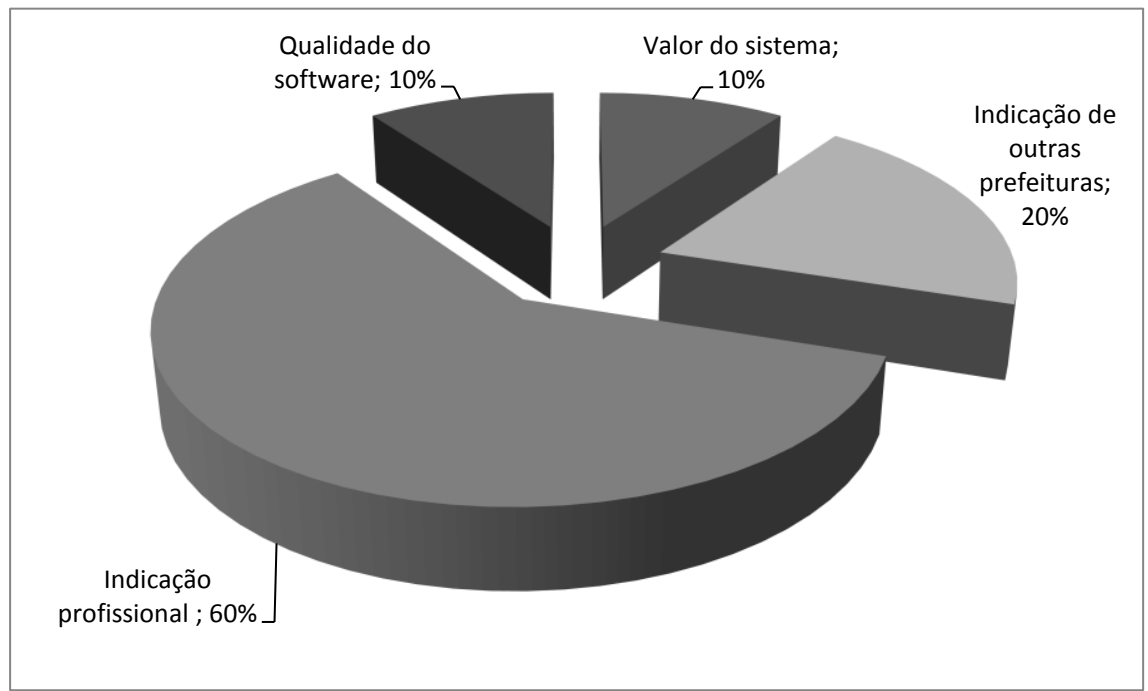

Figura 3. Distribuição dos fatores que influenciaram as prefeituras no momento da contratação do software

A questão dos critérios utilizados acabou revelando um aspecto bastante interessante. Embora não houvesse uma questão específica tratando a respeito da usabilidade dos produtos de software adquiridos, percebeu-se, durante as entrevistas, que havia uma preocupação dos participantes com esta questão. É interessante notar que embora esta preocupação tenha surgido na entrevista, não foi possível identificar que este tenha sido um critério de seleção utilizado durante o processo de aquisição. Alguns participantes informaram que o critério utilizado era a indicação de outro usuário, mas apesar disto, haviam visto uma demonstração do produto para ver sua facilidade de uso (embora a análise da interface tenha sido realizada de modo superficial).

\subsection{Utilização de boas práticas de aquisição}

Foi interesse desta pesquisa, identificar se no momento da contratação do sistema de gestão municipal alguma norma de boas práticas para gestão de aquisição de software foi observada (Q6). Os entrevistados tinham como opção de resposta algumas das normas mais utilizadas pelo mercado e que possuem guias para auxiliar nos processos de aquisição de software. Novamente constatou-se que $100 \%$ dos respondentes desconhecem os modelos de qualidade de software.

Não havia uma questão específica na pesquisa sobre processo de licitação, porém, cabe ressaltar que todos os entrevistados fizeram questão que constasse na pesquisa que o processo utilizado era o de licitação. Este processo procura alinhar o custo e a qualidade técnica, onde a qualidade técnica é avaliada levando-se em consideração itens como o tempo médio para prestação de suporte técnico, a unidade de serviço mais próxima e o tempo de atuação do fornecedor neste setor. Os entrevistados ainda alegaram que não colocaram como exigência certificação de nível de maturidade publicada por desconhecerem as normas e modelos de certificação, e ainda porque isso pode ser visto como uma tentativa de direcionar o certame para um determinado fornecedor. 


\subsection{Profissionais capacitados}

Finalmente, houve o interesse em compreender se, no quadro de funcionários das prefeituras respondentes, havia algum profissional que possuísse conhecimento sobre os modelos de boas práticas para aquisição de software, sendo assim capacitado para gerenciar os projetos de aquisição de software dentro da prefeitura. Dentre as opções de resposta estavam os modelos MPS, CMMI, eSCM-CL, ITIL e as normas ISO, porém $100 \%$ dos respondentes não possuíam profissionais capacitados em normas ou modelos de boas práticas de TI ou de qualidade para aquisição de software.

\section{Discussão dos resultados}

As questões Q1, Q2 e Q3 remetem a um cenário onde todas as prefeituras possuem software para auxiliar nas atividades de gestão pública; que a modalidade de outsourcing domina os processos de aquisição de software; e que uma empresa exerce domínio sobre este setor na questão de fornecimento de software nesta microrregião. $\mathrm{O}$ desconhecimento em relação ao nível de maturidade dos fornecedores de software foi constatado na questão Q4. Também ficou bem evidenciado durante a realização da entrevista nesta questão, que mesmo o pessoal responsável por TI, em sua maioria dedicados à parte de infraestrutura de hardware e redes, desconhecia a finalidade e os benefícios da implantação de procedimentos descritos definidos como de boas práticas para serem utilizadas durante o processo de aquisição de software.

Ficou claro durante as entrevistas, que havia uma preocupação dos participantes com a usabilidade do sistema, a eficiência do suporte técnico e o custo de aquisição. No entanto, estes não foram critérios decisivos na escolha do fornecedor. Por sua vez, itens como plataforma, integração do sistema, avaliação publicada de nível de maturidade e compromisso do fornecedor com a qualidade do software, são irrelevantes para os entrevistados.

Apesar de algumas prefeituras terem em seu quadro profissionais de TI concursados e com nível superior de escolaridade na área, eles dificilmente participam do processo de aquisição dos softwares de gestão. Isso foi constatado pela questão Q5, visto que o fator que mais influência o processo de outsourcing é a indicação de profissionais dos setores administrativos e contábil. Foi possível comprovar isso durante a pesquisa, onde, em $70 \%$ dos respondentes, a entrevista começou a ser realizada com profissionais responsáveis pela área de TI, devido ao enfoque tecnológico da pesquisa, porém, a partir da questão Q5 houve a participação de funcionários do setor administrativo, responsáveis pela parte de contratação de serviços e elaboração dos processos licitatórios.

As questões Q6 e Q7 foram fundamentais para análise do principal objetivo desta pesquisa. Foi possível constatar que não existe nos quadros funcionais das prefeituras pesquisadas, profissionais capacitados em boas práticas de TI e, consequentemente, nenhum modelo de boas práticas para aquisição de software é observado durante os processos de outsourcing de software para gestão pública. $\mathrm{O}$ processo licitatório é o único mecanismo observado na contratação de fornecedores de software, mas que atende apenas as questões legais. 


\section{Conclusões e trabalhos futuros}

Pode-se observar com esta pesquisa que, nas prefeituras que compõem a microrregião denominada AMCESPAR, nenhum modelo de boas práticas para aquisição de software é observado nos processos de outsourcing de software para gestão pública municipal.

Esta condição está atrelada, parcialmente, à falta de integração entre o departamento de TI das prefeituras, que deveria ser o setor responsável pela implementação dos modelos de boas práticas de TI, e o setor administrativo das instituições, ao qual cabe a observação dos aspectos legais dos processos de outsourcing de software. A falta de integração desses setores prejudica de forma substancial a qualidade dos processos de aquisição de software para gestão pública municipal, ainda que todos os aspectos legais sejam observados e cumpridos. O prejuízo para as instituições é imenso e pode ser facilmente constatado pelo fato de serem utilizados em uma mesma prefeitura sistemas de gestão pública de diferentes fornecedores e que não possuem qualquer tipo de integração.

Um ponto positivo, observado durante as entrevistas, é que tanto o setor de TI, quanto os setores administrativos, mostraram interesse em conhecer melhor as normas de boas práticas na aquisição de software para que possam implementá-las em seus processos futuros de outsourcing para aquisição de software.

Os próximos passos desta pesquisa são ampliar a abrangência deste estudo para outras microrregiões, de modo a comparar os resultados obtidos e compreender melhor os mecanismos utilizados nos processos de outsourcing de software em uma mesorregião. Pretende-se ainda, elaborar um framework, apoiado nas melhores práticas para aquisição de softwares existentes, com um modelo que seja adequado às peculiaridades dos municípios pesquisados.

\section{Referências Bibliográficas}

Abreu,F.P., Farias, P.P.M. , Albuquerque, A.B. (2010). Uma Abordagem Baseada em Definição de Requisitos e em Verificação e Validação para o Processo de Monitoração de Aquisição de Software. In: IX Simpósio Brasileiro de Qualidade de Software, Belém-PA.

AMCESPAR (2010). Associação dos Municípios da Região Centro Sul do Paraná. Disponível em http://www.amcespar.org.br. Acessado em dezembro 2010.

Cardoso, G. S. (2006). Processo de Aquisição de Produtos e Serviços de Software para Administração Pública do estado de Minas Gerais. Dissertação de Mestrado apresentada ao Curso de Pós-Graduação em Ciência da Computação da Universidade Federal de Minas Gerais.

Casey, V., Deshpande, S., Richardson, I (2008).Outsourcing Software Development the Remote Project Manager's Perspective.In: Second Information Systems Workshop on Global Sourcing: Services, Knowledge and Innovation.

Ferreira, J.A., Júnior, M.F.S., Souza,H.A (2008). Gerenciando a aquisição de software e serviços de TI na área pública. In: SEGeT - Simpósio de Excelência em Gestão e Tecnologia. 
Figueiredo, R.M.C., Bremer, C.F., Maldonado, J.C.(2003). Evolução dos modelos de outsourcing: o estado da arte da literatura dos novos provedores de serviços de aplicativos. Perspectivas em Ciência da Informação, v. 8, n. 1, p.40-57.

Gil, A. C (2002). Como elaborar projetos de pesquisa. 4. ed. São Paulo:Atlas.

ISO/IEC - International Organization For Standardization / International Electrotechnical Comission (1998). ISO/IEC TR 15504: parts 1-9 - Information technology - Software Process Assessment.

ITSqc - Information Technology Services Qualification Center (2009a), eSourcing Capability Model for Client Organizations (eSCM-CL) v1.1 - parte 1. Disponível em: http://www.itsqc.org/downloads/documents/eSCM-CL_Part1_V1dot1.html. Acessado em fevereiro/2011.

ITSqc - Information Technology Services Qualification Center (2009b), eSourcing Capability Model for Client Organizations (eSCM-CL) v1.1 - parte 2. Disponível em: $\quad$ http://www.itsqc.org/downloads/documents/eSCM-CL_Part2_V1dot1.html. Acessado em fevereiro/2011.

Laboratório Synergia (2006). Processo de aquisição de produtos e serviços de tecnologia da informação: Aplicação no estado de Minas Gerais (PrATIco).Disponível em http://pratico.synergia.dcc.ufmg.br/manual/. Acessado em fevereiro de 2010.

Lakatos, E. M., Marconi, M. A. (2005) Fundamentos da Metodologia Científica. 6. ed. São Paulo: Atlas.

Nunes, E., Barreto, A., Rocha, A. R.., Santos,G., Murta, L. (2010).Definição de Processos de Aquisição de Software para Reutilização. Artigo: COPPE/UFRJ, PPGI/UNIRIO, UFF- IC.

Santos, R.F. (2009). Identificação de Fatores que podem Influenciar nos Resultados de Contratos de software no Setor Público. Trabalho apresentado para conclusão de MBA em Administração Estratégica de Sistemas de Informação - FGV/DF.

Saraiva, L.A. S., Moura, S. R. (2010). Práticas políticas em relações empresariais de terceirização: um estudo de caso. Revista Economia e Gestão (PUCMG), v.10, n. 24.

SEI - Software Engineering Institute (2007), CMMI for Acquisition (CMMI-ACQ) Version 1.2. Disponível em: www.sei.cmu.edu/cmmi/tools/acq/download.cfm

SOFTEX - Associação para Promoção da Excelência do Software Brasileiro (2009a). Software e Serviços de TI: A Indústria Brasileira em Perspectiva.

SOFTEX - Associação para Promoção da Excelência do Software Brasileiro (2009b). MPS.BR - Melhoria de Processo do Software Brasileiro: Guia de Aquisição. Disponível em www.softex.br/mpsbr. Acessado em janeiro de 2011.

SOFTEX - Associação para Promoção da Excelência do Software Brasileiro (2011). Avaliações MPS vigentes. Disponível em www.softex.br/mpsbr. Acessado em janeiro de 2011.

Yin, R. (2005). Estudo de Caso: Planejamento e Métodos. 3. ed. Porto Alegre: Bookman. 